\title{
CMOS First-Order All-Pass Filter With 2-Hz Pole Frequency
}

\author{
Anindita Paul $^{\circledR}$, Student Member, IEEE, Jaime Ramírez-Angulo ${ }^{\circledR}$, Fellow, IEEE, \\ Antonio J. Lopez-Martin ${ }^{\circledR}$, Senior Member, IEEE, and \\ Ramón Gonzalez Carvajal, Senior Member, IEEE
}

\begin{abstract}
A CMOS fully integrated all-pass filter with an extremely low pole frequency of $2 \mathrm{~Hz}$ is introduced in this paper. It has $0.08-\mathrm{dB}$ passband ripple and $0.029-\mathrm{mm}^{2} \mathrm{Si}$ area. It has $0.38-\mathrm{mW}$ power consumption in strong inversion with $\pm 0.6-\mathrm{V}$ power supplies. In subthreshold, it has $0.64-\mu \mathrm{W}$ quiescent power and operates with \pm 200 - $\mathrm{mV}$ dc supplies. Miller multiplication is used to obtain a large equivalent capacitor without excessive Si area. By varying the gain of the Miller amplifier, the pole frequency can be varied from 2 to $48 \mathrm{~Hz}$. Experimental and simulation results of a test chip prototype in 130-nm CMOS technology validate the proposed circuit.
\end{abstract}

Index Terms-All-pass filter (APF), amplifier, Miller multiplier, operational transconductance amplifier (OTA), voltage follower.

\section{INTRODUCTION}

A LL-PASS FILTERS (APFs) have wide usage in signal processing [1]. They can be used in group delay (GD)/ phase equalizers, frequency-selective filters with a high-quality factor, etc. [2]. It is also an important block of quadrature and multiphase oscillators [3]. As it can provide time delay [4], it can be used in differential modulation and beamforming schemes [2] as well. A first-order APF introduces a $-90^{\circ}$ phase shift at a frequency $f_{0}$ (called pole frequency), whose value is inversely proportional to an $R C$ time constant. Most reported integrated APFs have a pole frequency $f_{0}$ in the kilohertz-gigahertz range [2], [5]-[10]. The goal of this paper is to implement a fully integrated APF with very low $f_{0}$ in the range of $\mathrm{Hz}$. This low $f_{0}$ frequency is necessary for some applications like in rotating disk viscometer [11], sensor-based medical devices that perform parallel processing [12] of the sensed biological signal which has frequencies below $100 \mathrm{~Hz}$ [13]. Viscometer can detect blood viscosity [14], which helps to determine many diseases [15] such as diabetes

Manuscript received July 2, 2018; revised September 14, 2018; accepted October 21, 2018. This work was supported by AEI/FEDER under Grant TEC2016-80396-C2. (Corresponding author: Anindita Paul.)

A. Paul and J. Ramírez-Angulo are with the Klipsch School of Electrical and Computer Engineering, New Mexico State University, Las Cruces, NM 88003 USA (e-mail: apaul03@nmsu.edu; jairamir@nmsu.edu).

A. J. Lopez-Martin is with the Department of Electrical and Electronic Engineering, Public University of Navarra, E-31006 Pamplona, Spain (e-mail: antonio.lopez@unavarra.es).

R. G. Carvajal is with the Department of Electronic Engineering, School of Engineering, University of Seville, 41092 Seville, Spain (e-mail: carvajal@gte.esi.us.es).

Color versions of one or more of the figures in this paper are available online at http://ieeexplore.ieee.org.

Digital Object Identifier 10.1109/TVLSI.2018.2878017 mellitus, malaria hypertension [16], and ischemic stroke [17]. The rotating disk viscometer needs uniformly rotating magnetic field which can be generated by two stable quadrature sinusoidal waveforms in the range of $0.5-50 \mathrm{~Hz}$. APFs can generate quadrature sinusoidal waveforms [3]. APFs can also be used to build linear phase equalizers which act as a delay line. This is necessary to provide synchronization between different parallel processing blocks of real-time signal processing medical devices such as electroencephalography [12] systems.

The frequency $f_{0}$ in the proposed $\mathrm{APF}$ is given by an expression of the form $f_{0}=1 /(2 \pi R C)$. Hence, to obtain a low-frequency $f_{0}$ in the $\mathrm{Hz}$ range, very large capacitor $C$ and resistor $R$ values are required. However, implementation of large capacitor and resistor values in standard CMOS technology with available conventional resistors and capacitors would take extremely large silicon area. In this paper, large valued resistors are implemented using the leakage resistance of the reverse biased source-bulk and drain-bulk $\mathrm{p}$-n junction within a pMOS transistor operating in the cutoff region. A large valued resistor can be emulated using switched-capacitor topology as well, where a two nonoverlapping clock needs to be generated [18]. A linear differential Miller amplifier is used to emulate large capacitors $(\sim 100 \mathrm{pF})$ using Miller effect from a moderately valued physical capacitor $C(\sim \mathrm{pF})$. These large valued resistances and capacitors can provide a very low cutoff frequency. By varying the gain of the Miller amplifier, variable Miller capacitors can be realized, which in turn provide adjustable pole frequencies which can be used to tune $f_{0}$ to compensate for manufacturing and temperature variations.

This paper is organized as follows. Section II describes the proposed APF circuit. A Miller multiplier used in the circuit is described in Section III. A comprehensive noise analysis of the proposed circuit is presented in Section IV. Simulation results for operation in strong inversion and subthreshold region are given in Section V. Section VI provides all experimental results. Finally, in Section VII, the conclusion of this paper is drawn.

\section{Description of the Proposed All-Pass Filter}

Due to its versatility, the linearized operational transconductance amplifier (OTA) is the basic building block of many linear and nonlinear analog circuits, such as continuous-time oscillator and filters [19], [20]. The proposed circuit is based 


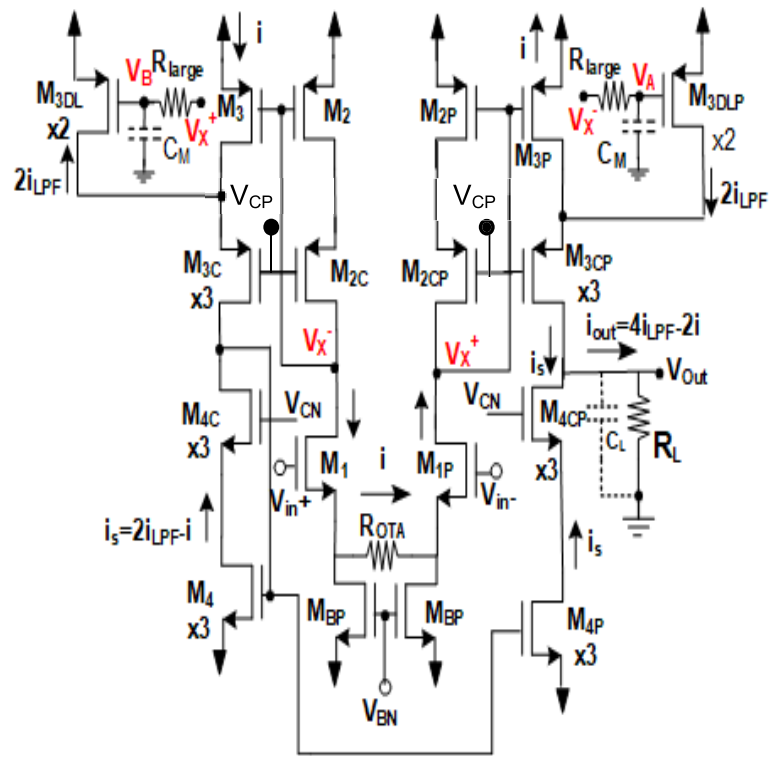

Fig. 1. Transistor level implementation of the proposed APF.

on a linear OTA architecture. The transistor level implementation of the APF is shown in Fig. 1. The differential input stage uses resistive degeneration to transform the differential input voltage $V_{d}=V_{\text {in }}^{+}-V_{\text {in }}^{-}$linearly into a signal current with value $i=V_{d} / R_{\mathrm{OTA}}$. The complementary signal currents, in $\mathrm{M}_{1}, \mathrm{M}_{1 \mathrm{P}}(i$ and $-i)$ are mirrored to the output branches of the OTA through two paths that add their currents in cascoded transistors $\mathrm{M}_{3 \mathrm{C}}, \mathrm{M}_{3 \mathrm{CP}}$. In one of the paths $\left(\mathrm{M}_{3}, \mathrm{M}_{3 \mathrm{P}}\right)$, the current $i$ is replicated with unity gain. In the second path (through $\mathrm{M}_{3 \mathrm{DL}}, \mathrm{M}_{3 \mathrm{DLP}}$ ), the current is mirrored with a current gain -2 and filtered by first-order $R C$ low-pass filters connected between nodes $V_{x}^{+}, V_{x}^{-}$, and nodes $V_{B}$ and $V_{\mathrm{A}}$ at the gates of $\mathrm{M}_{3 \mathrm{DL}}$ and $\mathrm{M}_{3 \mathrm{DLP}}$. Cross-connections are used to achieve inversion of the low-pass filtered currents $\left(i_{\mathrm{LPF}}\right)$ in $\mathrm{M}_{3 \mathrm{DL}}$ and M MDLP. The LPFs have a 3-dB frequency $\omega_{\mathrm{O}}=$ $1 /\left(R_{\text {large }} C_{M}\right)$ where $C_{M}$ is a Miller capacitance and $R_{\text {large }}$ are very high valued resistors. As the low-pass filtered current in $\mathrm{M}_{3 \mathrm{DL}}\left(\mathrm{M}_{3 \mathrm{DLP}}\right)$ is twice the current of $\mathrm{M}_{3}\left(\mathrm{M}_{3 \mathrm{P}}\right)$ and inverted as well, the resultant current $i_{s}$ is given by

$$
\begin{aligned}
i_{s}(\omega) & =2 i_{\mathrm{LPF}}(\omega)-i(\omega) \\
& =\left(V_{d}(\omega) / R_{\mathrm{OTA}}\right)\left(\frac{2}{\left(1+j \omega / \omega_{0}\right)}-1\right) \\
& =\left(V_{d}(\omega) / R_{\mathrm{OTA}}\right) \frac{\left(1-j \omega / \omega_{0}\right)}{\left(1+j \omega / \omega_{0}\right)} .
\end{aligned}
$$

The output voltage of the filter is given by

$$
\begin{aligned}
V_{\text {Out }}(\omega) & =\left(Z_{L} \| R_{\text {Out }}\right) i_{\text {out }}(\omega) \\
& =2\left(Z_{L} \| R_{\text {Out }}\right) i_{S}(\omega)
\end{aligned}
$$

where $R_{\text {Out }}$ is the output impedance of the OTA, buiding block of the APF. The load impedance of the filter is given by

$$
Z_{L}=\left(R_{L} \| X_{C}\right)=R_{L} /\left(1+j \omega C_{L} R_{L}\right) .
$$

Hence, using (1)-(3) the transfer function is given by

$$
H(j \omega)=\frac{2}{R_{\mathrm{OTA}}} \frac{\left(R_{L} \| R_{\mathrm{Out}}\right)}{\left(1+\frac{j \omega}{\omega_{\text {Pout }}}\right)}\left(\frac{\left(1-j \omega / \omega_{0}\right)}{\left(1+j \omega / \omega_{0}\right)}\right) .
$$

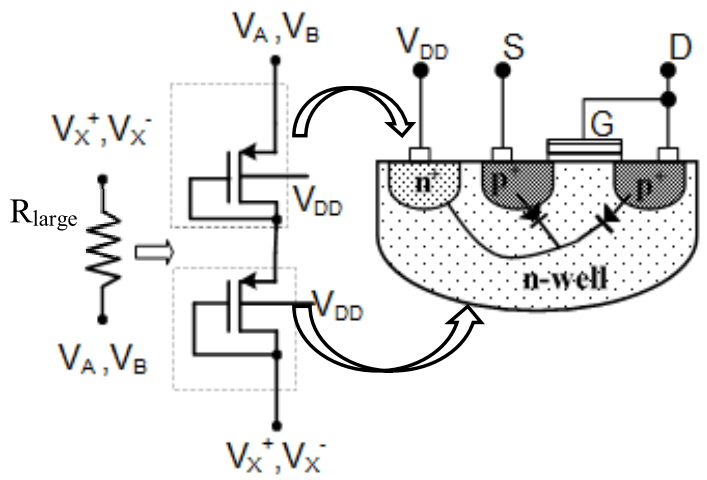

Fig. 2. Implementation of large resistor.

$R_{\text {Out }}$ can be expressed by $R_{\text {Out }}=g_{m} r_{o}^{2} / 2$ where $g_{m}$ is transconductance gain and $r_{\mathrm{O}}$ is output resistance of the output transistors. Assuming $R_{\text {Out }} \gg R_{L}$, the output pole of the filter is given by $\omega_{\text {pOut }} \approx 1 / R_{L} C_{L}$. Now, if $\omega_{0}$ is extremely small compared to the output pole $\omega_{\text {pOut }}\left(\omega_{0}<<<\omega_{\text {pOut }}\right)$ for frequencies $\omega<<<\omega_{\text {pOut }}$ (4) can be approximated by

$$
H(j \omega)=2\left(R_{L} / R_{\mathrm{OTA}}\right) \frac{\left(1-j \omega / \omega_{0}\right)}{\left(1+j \omega / \omega_{0}\right)} .
$$

Hence, (5) corresponds to the transfer function of a first-order APF with gain $K_{\text {fil }} \approx 2 R_{L} / R_{\text {OTA }}$ and pole frequency $f_{0}=$ $1 /\left(2 \pi R_{\text {large }} C_{M}\right)$. For $R_{\mathrm{OTA}}=2 R_{L}$, the APF has unity gain.

The two important characteristics of the first-order filters are its phase and GD. The phase response of the filter obtained from (5) is given by

$$
\phi=-2 \tan ^{-1}\left(\omega / \omega_{0}\right) .
$$

The GD of the APF is given by (7). GD variations are a measure of the phase nonlinearity. If there is a linear phase variation with frequency, GD must be constant. A first-order APF does not provide linear phase shift. However, by increasing the order of filter linear phase shift can be approximated

$$
\mathrm{GD}=-\frac{d \phi}{d \omega}=\frac{2}{1+\left(\omega / \omega_{0}\right)^{2}}\left(\frac{1}{\omega_{0}}\right) .
$$

The bandwidth $\left(\mathrm{BW}_{\mathrm{APF}}\right)$ of the APF is determined by the high-frequency dominant pole $f_{\text {pOut }}$ located at the output node $V_{\text {Out }}$. The $f_{\text {pOut }}$ can be expressed by (8) when $R_{L} \ll$ $R_{\text {Out }}$ and $C_{L}$ is the load capacitance

$$
f_{\mathrm{POut}}=\frac{1}{2 \pi R_{L} C_{L}} .
$$

The pole frequency $f_{0}$ with value in the order of $\mathrm{Hz}$ can be achieved by utilization of the leakage resistance of two diode-connected pMOS transistors operating in cutoff mode. Fig. 2 shows the implementation of these large valued resistances. From Fig. 2, it can be observed that two p-n junctions are formed. One is between the source and the n-well. The second one is between n-well and drains region. As the n-well is connected to $V_{\mathrm{DD}}$, the $\mathrm{p}-\mathrm{n}$ junctions are reverse biased. The leakage resistance of these reversed biased $p-n$ junctions provides a very large resistance when the diode-connected pMOS is in cutoff region. These two large valued resistors are connected to the gate of the $\mathrm{M}_{3 \mathrm{DL}}$ and $\mathrm{M}_{3 \mathrm{DLP}}$ in Fig. 1 and 


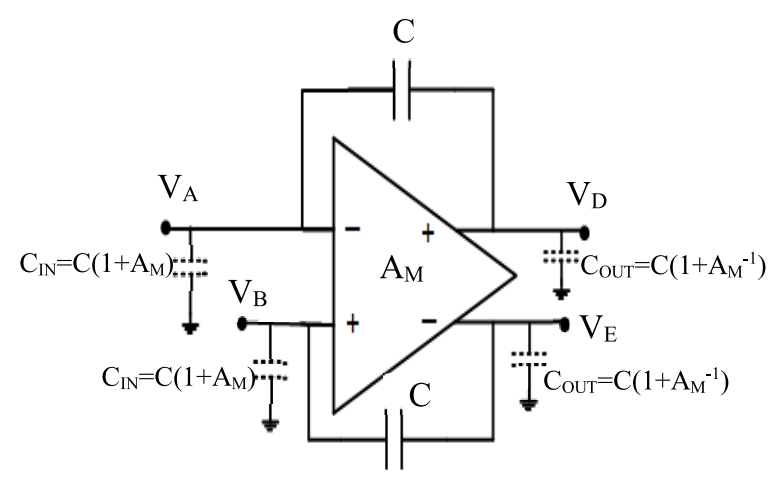

(a)

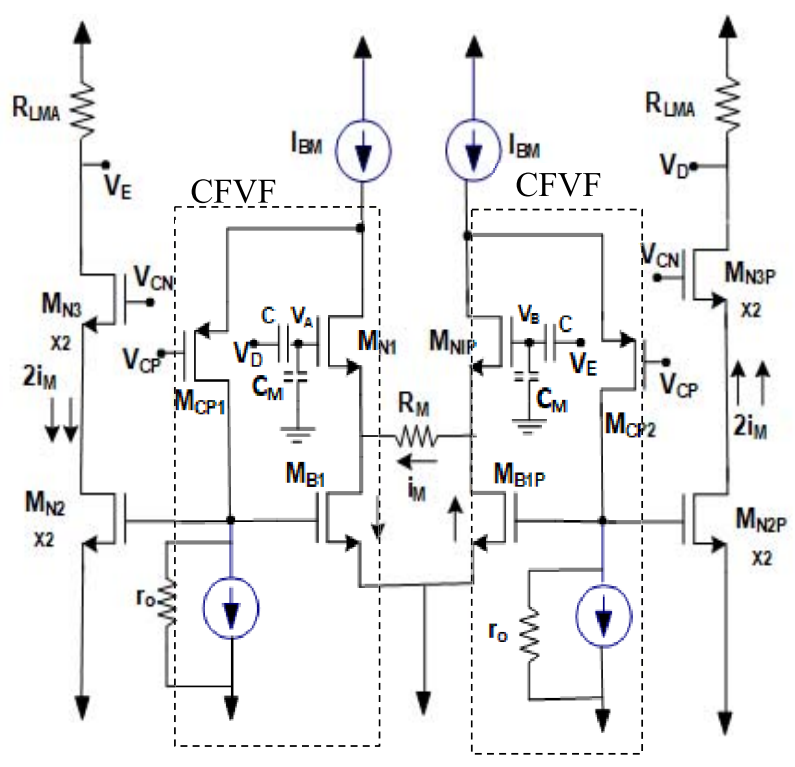

(b)

Fig. 3. (a) Block diagram of differential Miller amplifier. (b) Circuit implementation of linear Miller amplifier.

provide well-controlled dc gate bias voltage. These two transistors are called quasi-floating gate transistors [21], [22]. This technique has been used to implement extremely large resistors $\left(R_{\text {large }} \sim 10-100 \mathrm{G} \Omega\right.$ ) for many applications [23]. Miller multiplication effect is also used in this paper to emulate large capacitors from relatively low valued physical capacitors depending on the gain of the amplifier (in the example presented here $C_{M} \approx 310 \mathrm{pF}$ ). The Miller multiplier circuit is described in Section III.

\section{Miller Multiplier}

A large capacitance without excessive silicon area requirements is implemented using Miller multiplication [24], as shown in Fig. 3(a). Here, capacitors $(C)$ are connected between the input and output of an inverting amplifier with gain $-A_{M}$. This leads to an input Miller capacitance with value $C_{M}=C\left(1+A_{M}\right)$. The linear amplifier used for this purpose is shown in Fig. 3(b). It has a similar structure as reported in [25] and [26]. It is comprised a linear voltage to current converter using two cascoded flipped voltage

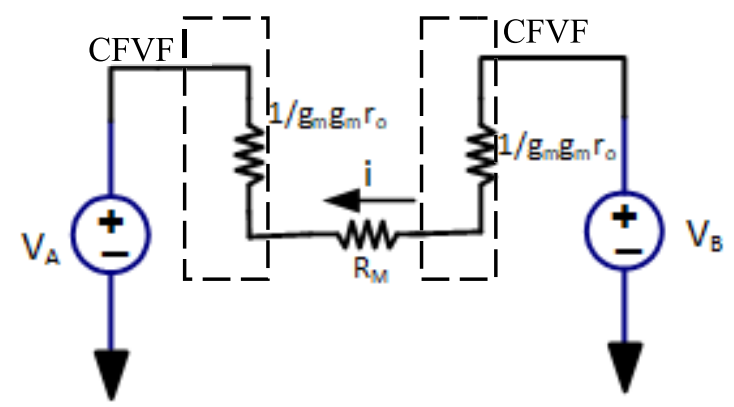

Fig. 4. Equivalent circuit of the input stage of Miller amplifier.

followers (CFVFs) [27] in a differential configuration at the input stage. A pMOS cascode transistor $\mathrm{M}_{\mathrm{CP} 1, \mathrm{CP} 2}$ connected between the drain of $M_{N 1, N 1 P}$ and the gate of $M_{B 1, B 1 P}$ in Fig. 3(b) provides local negative feedback. The drain currents in $\mathrm{M}_{\mathrm{N} 1}$ and $\mathrm{M}_{\mathrm{N} 1 \mathrm{P}}$ are constant and independent of the input voltage. Hence, neglecting second-order effects $V_{\mathrm{GSMN}}$ and $V_{\mathrm{GSMN} 1 \mathrm{P}}$ are constant. The CFVFs act as high-performance buffers with very low output resistance $r_{\mathrm{outCFVF}}=1 /\left(g_{m} g_{m} r_{o}\right)$ at the sources of $\mathrm{M}_{\mathrm{N} 1}$ and $\mathrm{M}_{\mathrm{N} 1 \mathrm{P}}$. In the example shown later, the value of $\mathrm{r}_{\text {outCFVF }}$ is $72 \Omega$ and $R_{M}=1.5 \mathrm{k}$. Hence, $r_{\mathrm{outCFV}} \ll R_{M}$. This validates that the input stage of the capacitance multiplier is linear. The equivalent circuit of the input stage is shown in Fig. 4. The differential input voltage $V_{\text {indiff }}=\left(V_{B}-V_{A}\right)$ at the gates of $\mathrm{M}_{\mathrm{N} 1 \mathrm{P}}$ and $\mathrm{M}_{\mathrm{N} 1}$ is transferred to $R_{M}$. This leads to a signal current given by

$$
i_{M}=\left(V_{\mathrm{B}}-V_{\mathrm{A}}\right) / R_{M}=V_{\text {indiff }} / R_{M} .
$$

Current $i_{M}$ flows in $R_{M}$ and in $\mathrm{M}_{\mathrm{B} 1}$ and $\mathrm{M}_{\mathrm{B} 1 \mathrm{P}}$. Transistors $\mathrm{M}_{\mathrm{N} 2}, \mathrm{M}_{\mathrm{N} 2 \mathrm{P}}$ are scaled up by a factor of two with respect to transistors $\mathrm{M}_{\mathrm{B} 1}, \mathrm{M}_{\mathrm{B} 1 \mathrm{P}}$. Hence, the current $i$ is replicated in the output branches $\left(\mathrm{M}_{\mathrm{N} 3}\right.$ and $\left.\mathrm{M}_{\mathrm{N} 3 \mathrm{P}}\right)$ with a value twice of $i_{M}$ and flows in the load resistors $R_{\mathrm{LMA}}$. Hence, the single-ended signal output voltages are given by

$$
V_{\text {outMSE }}=V_{D}=-V_{E}=2 i_{M} R_{\mathrm{LMA}} .
$$

The voltage gain of the Miller amplifier with respect to differential input signal has a value $A_{\text {Mdiff }}=V_{\text {outMSE }} / V_{\text {indiff }}=$ $2 R_{\mathrm{LMA}} / R_{M}$. Hence, the voltage gain of the capacitance multiplier of one output with respect to a single-ended input is given by

$$
A_{M}=-V_{\text {outMSE }} /\left(V_{\text {indiff }} / 2\right)=-4\left(R_{\mathrm{LMA}} / R_{M}\right) .
$$

In this paper, values of $R_{\mathrm{LMA}}=12 \mathrm{k} \Omega$ and $R_{M}=1.5 \mathrm{k} \Omega$ are used for the capacitance multiplier. The bias current has a value of $I_{\mathrm{BM}}=40 \mu \mathrm{A}$, and the voltage gain of the capacitance multiplier is $A_{M} \approx-32$. The resultant Miller multiplication factor is $K_{M}=\left(1-\left(-A_{M}\right)\right)=33$. The capacitor $C$ has a value of $10 \mathrm{pF}$. This results in a Miller capacitance $C_{M}=330 \mathrm{pF}$. The silicon area occupied by this amplifier with two $10-\mathrm{pF}$ capacitors $(C)$ is $0.012 \mathrm{~mm}^{2}$. If two $330-\mathrm{pF}$ capacitors had been used instead of the Miller multiplier, it would occupy $0.245 \mathrm{~mm}^{2}$. Hence, 21 times area was saved at the expense of $192 \mu \mathrm{W}$ consumed by the Miller multiplier.

If required, the pole frequency $f_{0}$ of the APF can be programed by adjusting $R_{\mathrm{LMA}}$, which controls the Miller 


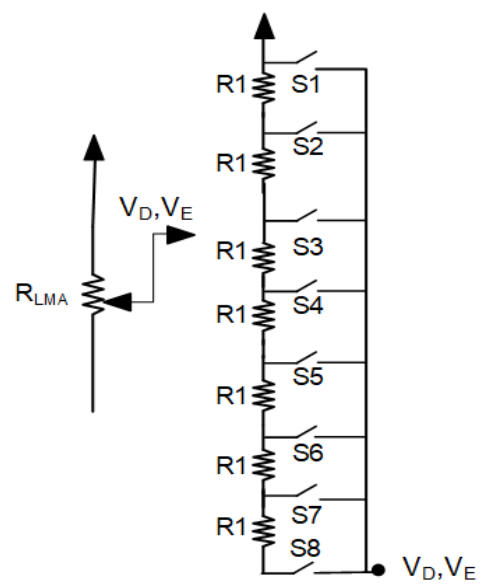

Fig. 5. Implementation of variable resistors.

multiplication factor $K_{M}=1-A_{M}=1+4 R_{\mathrm{LMA}} / R_{M}$. This is useful if $f_{0}$ needs to be tuned to compensate for manufacturing and/or temperature variations. Temperature dependence and manufacturing tolerances are common problems in all continuous time integrated filters [28], [29]. The programmability can be done by implementing variable $R_{\mathrm{LMA}}$ using switches as shown in Fig. 5. They connect one terminal of capacitor $C$ to a tap in $R_{\mathrm{LMA}}$. This causes the effective $R_{\mathrm{LMAeff}}$ to take values from 0 to $7 \mathrm{R} 1$, which corresponds to a capacitance multiplication factor $K_{M}$ varying from 1 to 33 . The unit resistor value is $R_{\text {LMAunit }}=R 1=1.71 \mathrm{k} \Omega$ and $R_{M}=1.5 \mathrm{k} \Omega$. One way to tune the APF is to use an external accurate reference clock and scale down its frequency using digital frequency dividers to derive a reference delay that can be tuned to the delay of the proposed APF (this is dependent on the pole frequency). The APF would be tuned with the gain of the Miller Amplifier until the delay derived from the APF and the reference delay derived from the external clock match.

The APF of Fig. 1 can be implemented as a fully differential circuit by replacing the nMOS current mirror at the bottom $\left(\mathrm{M}_{4}, \mathrm{M}_{4 \mathrm{P}}, \mathrm{M}_{4 \mathrm{C}}, \mathrm{M}_{4 \mathrm{CP}}\right)$ by current sources. This is done by simply opening the diode connection of $\mathrm{M}_{4}$ and taking a complementary output at the drain of $\mathrm{M}_{4 \mathrm{C}}$ and connecting the gates of $\mathrm{M}_{4}, \mathrm{M}_{4 \mathrm{P}}$ to the dc biasing voltage $V_{\mathrm{BN}}$.

\section{NOISE ANALYSIS OF APF}

In this section, noise analysis of the APF is provided. Fig. 6 shows the noise sources contributed by the transistors and resistors. Noise generated by cascode transistors, and $R_{\text {large }}$ elements have negligible contribution to input referred noise. $R_{\text {large }}$ elements are implemented using reverse biased p-n junctions of diode connected pMOS transistor operating in cutoff, which do not show thermal or flicker noise. The noise of the APF is due to thermal noise generated by the MOS transistors and resistors and flicker noise originating from MOS transistors only. Now, as the APF works in low frequency around $f_{0}$, flicker noise is predominant in the low-frequency range [30].

Total noise currents at nodes $V_{x}^{+}, V_{x}^{-}$generated in the input stage are mirrored to the output stage by transistors $\mathrm{M}_{3,3 \mathrm{p}}$ with

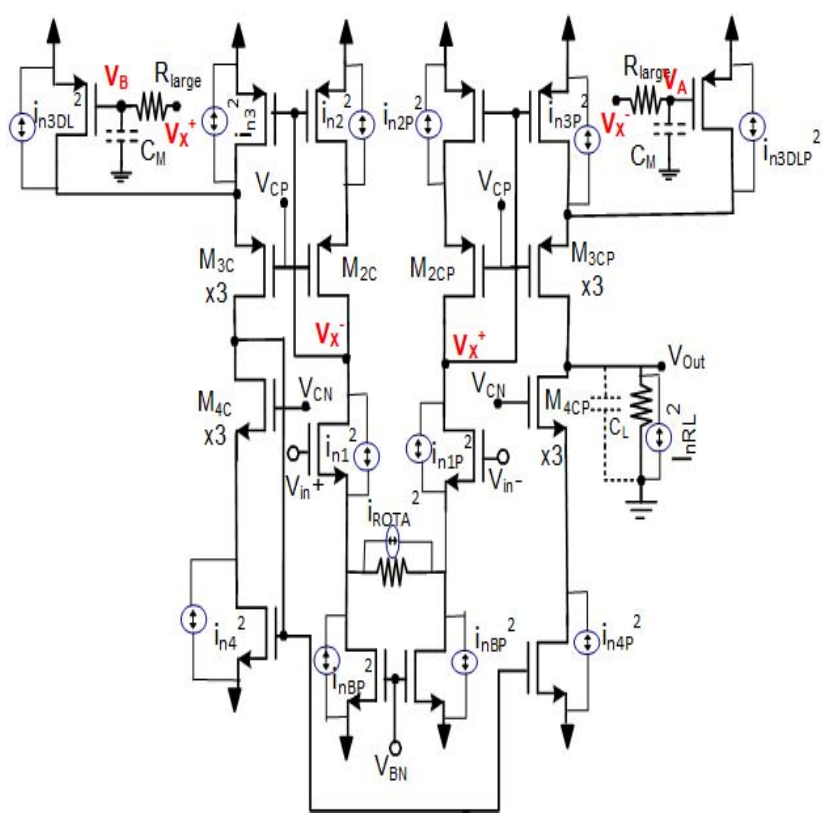

Fig. 6. Noise sources of APF.

a 1:1 gain factor and by transistors $\mathrm{M}_{3 \mathrm{DL}, 3 \mathrm{DLP}}$ with a 1:2 gain factor.

The total flicker noise current per unit BW in the input stage at nodes $V_{x}^{+}, V_{x}^{-}$is given by

$$
\overline{i_{\mathrm{inAPFf}}^{2}}=2\left[\overline{i_{\mathrm{nBPf}}^{2}}+\overline{i_{1 f}^{2}}+\overline{i_{2 f}^{2}}\right] .
$$

The effective transconductance gain $G_{\text {meffinp }}$ of $\mathrm{M}_{1}$ due to source degeneration is $G_{\text {meffinp }}=\left(g_{m 1} /\left(1+g_{m 1} R_{\mathrm{OTA}} / 2\right)\right)$. The flicker noise current (per unit $\mathrm{BW}$ ) contribution at nodes $V_{x}^{+}, V_{x}^{-}$coming from the tail current source transistors $\mathrm{M}_{\mathrm{BP}}$ is given by

$$
{\overline{i_{n \mathrm{BPf}}}}^{2}=\frac{K}{C_{\mathrm{OX}}(W L)_{\mathrm{BP}}} \frac{g_{m \mathrm{BP}}^{2}}{f}\left(\frac{R_{\mathrm{OTA}} / 2}{1 / g_{m 1}+R_{\mathrm{OTA}} / 2}\right)^{2}
$$

where $K$ is a process-dependent constant [30]. The flicker noise currents (per unit BW) contributions at nodes $V_{x}^{+}, V_{x}^{-}$ from $\mathrm{M}_{1,1 \mathrm{P}}, \mathrm{M}_{2}, 2 \mathrm{P}, \mathrm{M}_{3}, 3 \mathrm{P}, \mathrm{M}_{4}, 4 \mathrm{P}$, and $\mathrm{M}_{3 \mathrm{DL}}$, 3DLP are given by

$$
\begin{aligned}
{\overline{i_{1 f}}}^{2} & =\frac{K}{C_{\mathrm{OX}}(W L)_{1}} \frac{1}{f}\left(\frac{g_{m 1}}{1+g_{m 1} R_{\mathrm{OTA}} / 2}\right)^{2} \\
& \approx \frac{K}{C_{\mathrm{OX}}(W L)_{1}} \frac{1}{f}\left(\frac{1}{R_{\mathrm{OTA}} / 2}\right)^{2} \\
{\overline{i_{2 f}}}^{2} & =\frac{K}{C_{\mathrm{OX}}(W L)_{2}} \frac{g_{m 2}^{2}}{f} \\
{\overline{i_{3 f}}}^{2} & =\frac{K}{C_{\mathrm{OX}}(W L)_{3}} \frac{g_{m 3}^{2}}{f} \\
{\overline{i_{3 \mathrm{DL} f}}}^{2} & =\frac{K}{C_{\mathrm{OX}}(W L)_{3 \mathrm{DL}}} \frac{g_{m 3 \mathrm{DL}}^{2}}{f} \\
{\overline{i_{4 f}}}^{2} & =\frac{K}{C_{\mathrm{OX}}(W L)_{4}} \frac{g_{m 4}^{2}}{f} .
\end{aligned}
$$

The total output flicker noise current per unit BW resulting from the output stage transistors and the currents mirrored 
from the input stage are

$$
\left.\overline{i_{\text {OutAPFf }}^{2}}=25\left(\overline{i_{n \mathrm{BPf}}^{2}}+\overline{i_{1 f}^{2}}+\overline{i_{2 f}^{2}}\right)+\overline{i_{3 f}^{2}}+\overline{i_{4 f}^{2}}+\overline{i_{3 \mathrm{DLf}}^{2}}\right] .
$$

The output flicker noise voltage per unit BW is

$$
\overline{V_{\text {outnf }}^{2}}=\overline{i_{\text {OutAPFf }}^{2}} R_{L}^{2} \text {. }
$$

From the transfer function of the filter given in (5), the gain of the filter is 1 from dc till $100 \mathrm{kHz}$. Hence, the input referred flicker noise voltage at $\omega_{0}$ is

$$
\overline{V_{\text {inf }}^{2}}=\overline{i_{\text {OutAPFf }}^{2}} R_{L}^{2}
$$

The source of another noise is thermal noise of MOSFET and resistors $R_{\mathrm{OTA}}$ and $R_{L}$. The total thermal input noise current spectral density originating from $\mathrm{M}_{1}, \mathrm{M}_{\mathrm{BP}}, \mathrm{M}_{2}$, and $R_{\text {OTA }}$ reaching nodes $V_{x}^{+}, V_{x}^{-}$are given by

$$
\overline{i_{\text {inAPFT }}^{2}}=2\left[\overline{i_{n \mathrm{BPT}}^{2}}+\overline{i_{1 T}^{2}}+\overline{i_{2 T}^{2}}+\overline{i_{R \mathrm{OTA}}^{2}}\right] .
$$

Thermal noise currents contributions per unit BW at nodes $V_{x}^{+}, V_{\mathrm{x}}^{-}$from the tail current source $\mathrm{M}_{\mathrm{BP}}$ and input differential pair are given in the following equations:

$$
\begin{aligned}
{\overline{i_{1 T}}}^{2} & =\frac{4 k T \gamma}{g_{m 1}}\left(\frac{g_{m 1}}{1+g_{m 1} R_{\mathrm{OTA}} / 2}\right)^{2} \\
& \approx \frac{4 k T \gamma}{g_{m 1}}\left(\frac{1}{R_{\mathrm{OTA}} / 2}\right)^{2} \\
{\overline{i_{n \mathrm{BPT}}}}^{2} & =4 k T \gamma g_{m \mathrm{BP}}\left(\frac{R_{\mathrm{OTA}} / 2}{1 / g_{m 1}+R_{\mathrm{OTA}} / 2}\right)^{2} .
\end{aligned}
$$

The thermal noise current contribution at nodes $V_{x}^{+}, V_{x}^{-}$from $R_{\text {OTA }}$ can be expressed by (24). $k$ is Boltzmann's constant

$$
\left.\overline{i_{R \mathrm{OTAT}}^{2}}=\frac{4 k T}{R_{\mathrm{OTA}} / 2}\left(\frac{R_{\mathrm{OTA}} / 2}{R_{\mathrm{OTA}} / 2+1 / g_{m 1}}\right)^{2}\right] \text {. }
$$

The thermal noise current contributions per unit BW from the elements in the output stage $\left(\mathrm{M}_{3}, \mathrm{M}_{4}, \mathrm{M}_{3 \mathrm{DL}}\right.$, and $\left.R_{L},\right)$ are given by

$$
\begin{aligned}
& \overline{i_{n T 3,4,3 \mathrm{DL}, R_{L}}^{2}} \\
& \quad=2\left[4 k T \gamma g_{m 3}+4 k T \gamma g_{m 4}+4 k T \gamma g_{m 3 D L}+\frac{4 k T}{R_{L}}\right] .
\end{aligned}
$$

The output thermal noise voltage per unit BW resulting from the noise currents in the input stage mirrored to the output stage and the currents generated in the output stage is given by

$$
\overline{V_{\text {out } n T}^{2}}=\overline{i_{\text {OutAPFT }}^{2}} R_{L}^{2}
$$

where

$$
\begin{aligned}
& \left.\overline{i_{\text {OutAPFT }}^{2}}=25 \overline{i_{n \mathrm{BPT}}^{2}}+\overline{i_{n 1 T}^{2}}+\overline{i_{n 2 T}^{2}}+\overline{i_{n \mathrm{ROTAT}}^{2}}\right) \\
& \left.+\overline{i_{n T 3,4,3 \mathrm{DL}, R_{L}}^{2}}\right] \text {. }
\end{aligned}
$$

Like flicker noise, it can be asserted that as the filter has magnitude gain of 1 the input referred thermal noise voltage per unit BW is $\overline{V_{\mathrm{in} T}^{2}}=\overline{i_{\text {outAPFT }}^{2}} R_{L}^{2}$. Hence, total input referred noise voltage of the APF per unit BW is $\overline{V_{\text {intotal }}^{2}}=\overline{V_{\text {in } f}^{2}}+\overline{V_{\text {inT }}^{2}}$.

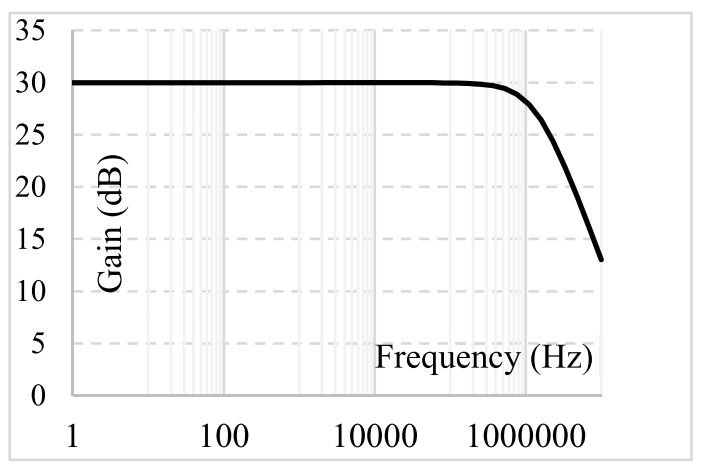

Fig. 7. Single-ended magnitude response of Miller amplifier.

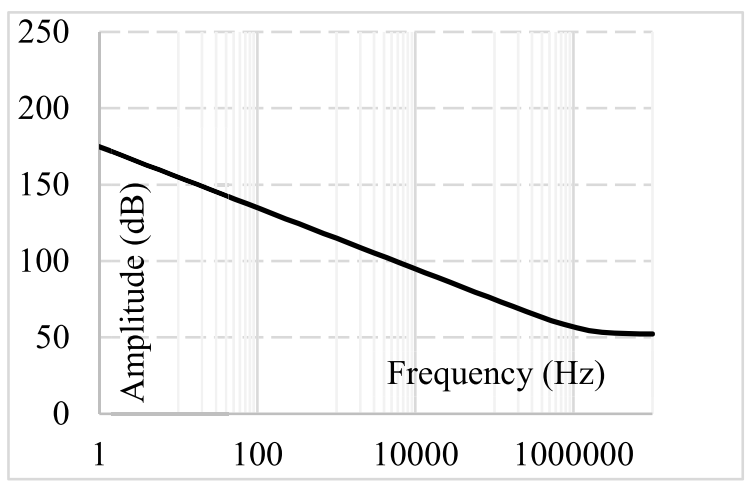

Fig. 8. Magnitude response of impedance $C_{M}$ at the input of Miller amplifier.

For the design reported here with unit transistor size $(W / L)_{\mathrm{N}}=6.65 / 0.27,(W / L)_{\mathrm{P}}=33.75 / 0.27, g_{m 1}=$ $864 \mu \mathrm{A} / \mathrm{V}$, and $f=2 \mathrm{~Hz}$, process-dependent constant $K=$ $1 \times 10^{-25}, C_{\mathrm{ox}}=1 \times 10^{-15} \mathrm{f} / \mu \mathrm{m}^{2}, R_{\mathrm{OTA}}=10 \mathrm{k} \Omega$, and $R_{L}=5 \mathrm{k} \Omega$ flicker noise spectral density is $75.9 \mu \mathrm{V} / \sqrt{ } \mathrm{Hz}$ at $f_{0} . K$ and $C_{\mathrm{OX}}$ are obtained from the technology design kit. For thermal noise calculation Boltzmann's constant $k$ is = $1.38 \times 10^{-23}$, and $T$ is $300^{\circ} \mathrm{k}$. Thermal noise is $80 \mathrm{nV} / \sqrt{ } \mathrm{Hz}$ at $f_{0}$. As expected, $1 / f$ noise is dominant over thermal noise in the range of $f_{0}$.

\section{Simulation Results}

\section{A. Simulation in Strong Inversion}

The circuits of Figs. 1 and 3(b) were designed and simulated in a 130-nm CMOS technology with values $R_{\text {OTA }}=$ $10 \mathrm{k} \Omega, R_{M}=1.5 \mathrm{k} \Omega$, capacitor $C=10 \mathrm{pF}$, unit transistor sizes (in micrometers) of $33.76 / 0.27$ (pMOS) and 6.67/0.27 (nMOS), $\pm 0.6-\mathrm{V}$ dual supply voltages ( $V_{\mathrm{DD}}$ and $V_{\mathrm{SS}}$ ), a load $R_{L}=5 \mathrm{k} \Omega, C_{L}=25 \mathrm{pF}$, a bias current $I_{B}=20 \mu \mathrm{A}$, and $R_{\mathrm{LMA}}=12 \mathrm{k} \Omega$. The magnitude response $A_{M}$ of the Miller amplifier is shown in Fig. 7. From Fig. 7, it can be observed that the single-ended gain for the inverting amplifier is $30 \mathrm{~dB} \approx 31.62 \mathrm{~V} / \mathrm{V}$ instead of $32 \mathrm{~V} / \mathrm{V}$. The moderate reduction happens due to body effect from gate to source of transistors $\mathrm{M}_{\mathrm{N} 1}$ and $\mathrm{M}_{\mathrm{N} 1 \mathrm{P}}$ at the input of the Miller multiplier Fig. 3(b). This result complies with the theoretical value of the gain of the inverting amplifier which is given by $32 \mathrm{~V} / \mathrm{V}$. The magnitude and phase of the impedance of $C_{M}$ at the input of the Miller multiplier are shown in Figs. 8 and 9, respectively. It can be seen that as the frequency increases 
This is the author's version of an article that has been published in this journal. Changes were made to this version by the publisher prior to publication.

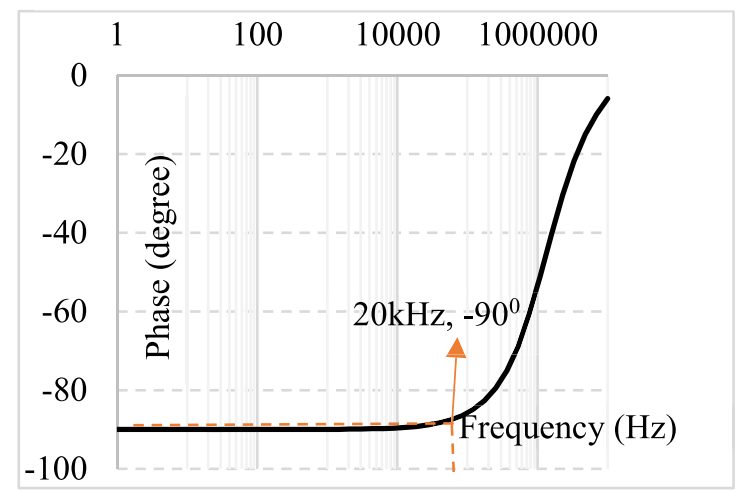

Fig. 9. Phase response of impedance $C_{M}$ at the input of Miller amplifier.

TABLE I

POLE FREQUENCY AND THD (300-mV AMPLITUdE SINUSOIDAL SignAL) AT FOUR CORNERS

\begin{tabular}{|l|l|l|l|l|}
\hline & tt & fs & ss & ssf \\
\hline Pole frequency $(\mathrm{Hz})$ & 2.03 & 2.02 & 2.08 & 2.04 \\
\hline THD $(\mathrm{dB})$ & -48 & -44 & -48 & -40 \\
& & & & \\
\hline
\end{tabular}

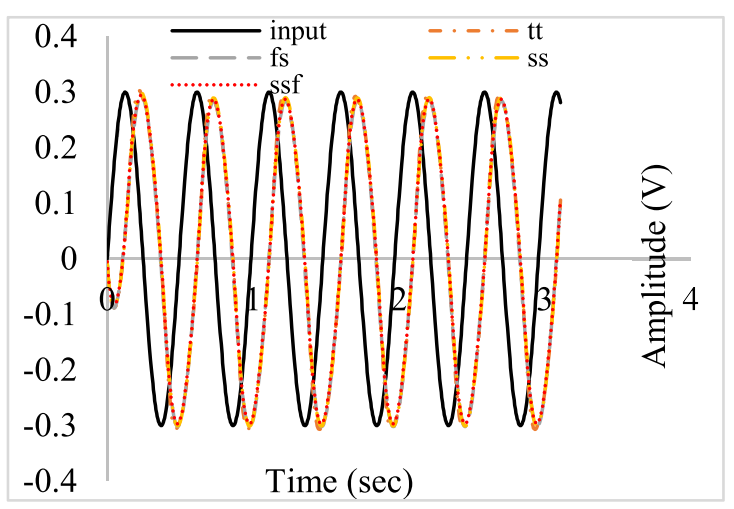

Fig. 10. Transient response at four different corners.

impedance decreases at a constant rate of $20 \mathrm{~dB} /$ decade and that the phase is close to $-90^{\circ}$ up untill $20 \mathrm{kHz}$. This behavior complies with the actual behavior of the reactance of a capacitor. At $2 \mathrm{~Hz}$, the impedance is approximately $256 \mathrm{M} \Omega$. As $X_{C}=1 /(j \omega C)$, the value of $C$ is $310 \mathrm{pF}$ at $2 \mathrm{~Hz}$. Therefore, Miller multiplication makes it possible to emulate a $310-\mathrm{pF}$ capacitor from a $10-\mathrm{pF}$ base capacitor. Total harmonic distortion and pole frequency of the APF at four different corners (tt, ss, fs, and ssf) are given in Table I. The transient response of the APF is shown in Fig. 10 at four different corners. The simulated value of the pole frequency is given in Fig. 11 at four different corners. The standard deviation of the pole frequencies at four different corners is $0.03 \mathrm{~Hz}$. A consistent pole frequency of the filter at four different corners has been obtained. THD has been calculated for each corner for a 300-mV amplitude sinusoidal input signal and given in Table I. The standard deviation of THD is $3.8 \mathrm{~dB}$. Fig. 12 shows the equivalent input noise of the APF. From Fig. 12, it can be observed that as expected, at low-frequencies flicker noise is predominant. The measured value of the flicker noise at $2 \mathrm{~Hz}(84 \mu \mathrm{V} / \sqrt{ } \mathrm{Hz})$ is very close to its theoretical

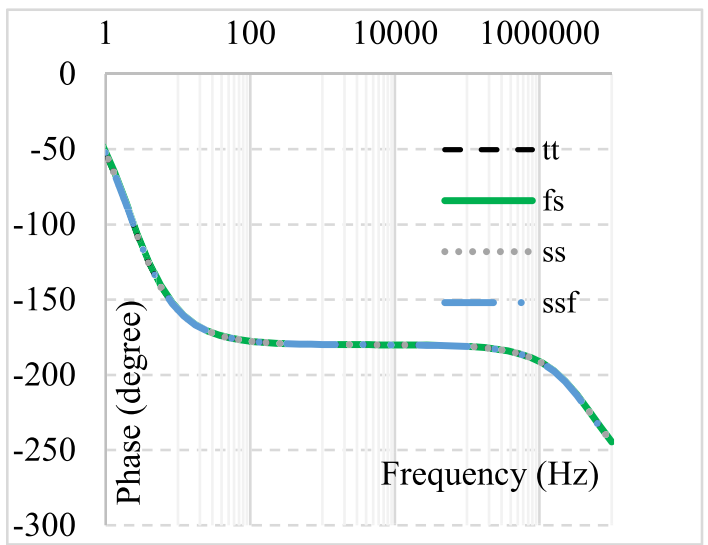

Fig. 11. Phase response of APF at four different corners.

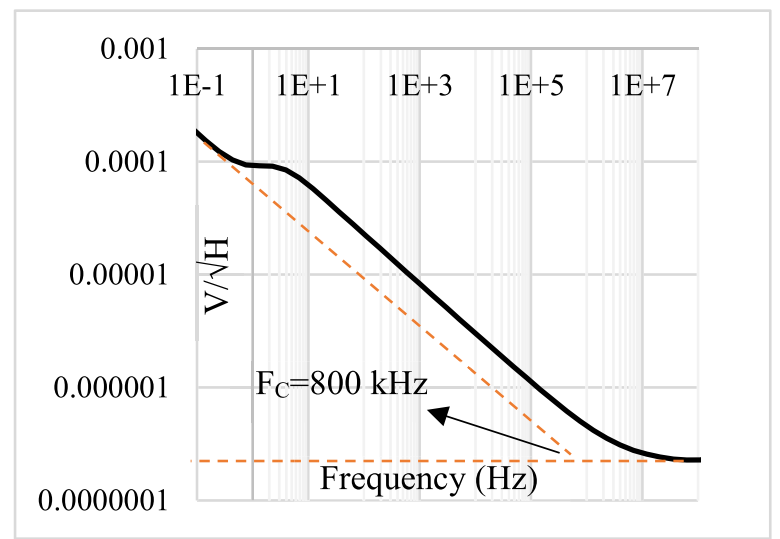

Fig. 12. Equivalent input noise of APF.

value (75.9 $\mu \mathrm{V} / \sqrt{ } \mathrm{Hz}$ ) obtained from (20). Total $\mathrm{rms}$ noise can be found from [31]

$$
V_{n, \mathrm{rms}}\left(F_{L}, F_{H}\right)=V_{\mathrm{nW}} \sqrt{F_{\mathrm{C}} \ln \left(F_{H} / F_{L}\right)+\left(F_{H}-F_{L}\right)}
$$

where $V_{\mathrm{nw}}$ is the white noise spectral density determined from simulations, $F_{L}$ is the lowest frequency of interest in $1 / f$ region, and $F_{C}$ is corner frequency where power density of flicker noise and thermal noise are equal. $F_{C}$ is $800 \mathrm{kHz}$ as shown in Fig. 12. $F_{H}$ is the equivalent noise BW that corresponds to $\mathrm{QBW}_{\text {noise }}=(\pi / 2) f_{3 \mathrm{~dB}}$. Using $F_{H}=1.57 \mathrm{MHz}$, $F_{L}=0.1 \mathrm{~Hz}, F_{C}=800 \mathrm{kHz}$, and $V \mathrm{nw}=228 \mathrm{nV} / \sqrt{ } \mathrm{Hz}$ in (28) a value $V_{n \mathrm{rms}}=0.8 \mathrm{mV}_{\mathrm{rms}}$ is calculated.

The pole frequency can be varied by changing the gain of the Miller amplifier. The simulated magnitude and phase responses corresponding to the eight possible effective load resistances $R_{\mathrm{LMA}}=0, R 1,2 R 1,3 R 1,4 R 1,5 R 1,6 R 1,7 R 1$ are shown in Figs. 13 and 14. The pole frequencies $f_{0}$ vary from 2.03 to $48.62 \mathrm{~Hz}$ by varying the gain $A_{M}$ for different values of $R_{\mathrm{LMA}}$ of the amplifier.

\section{B. Simulation in the Subthreshold Region}

The APF can work in the subthreshold region as well with an essentially lower bias current $I_{B}=100 \mathrm{nA}$. For this current, the output pole frequency has a value of $f_{\text {pOut }}=2 \mathrm{kHz}$. This is still at a much higher frequency than frequency $f_{0}$ which is close to $2.8 \mathrm{~Hz}$. In this case, the supply voltage 
This is the author's version of an article that has been published in this journal. Changes were made to this version by the publisher prior to publication.

The final version of record is available at https://doi.org/10.1109/TVLSI.2018.2878017

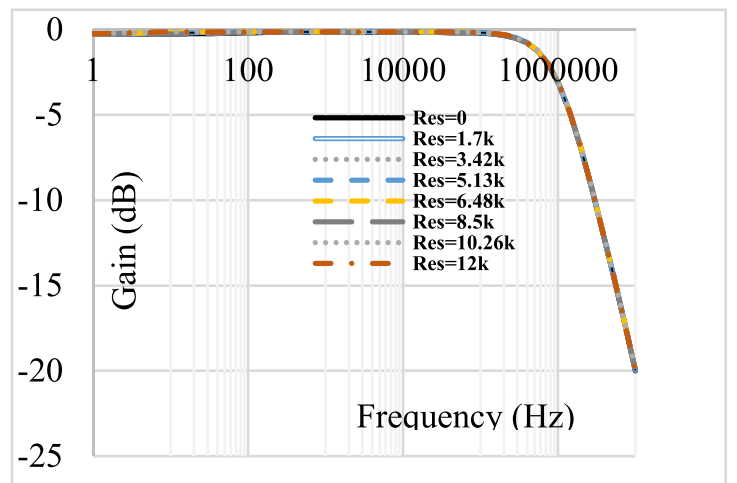

Fig. 13. Magnitude response for different values of gain for varying $R_{\mathrm{LMA}}$

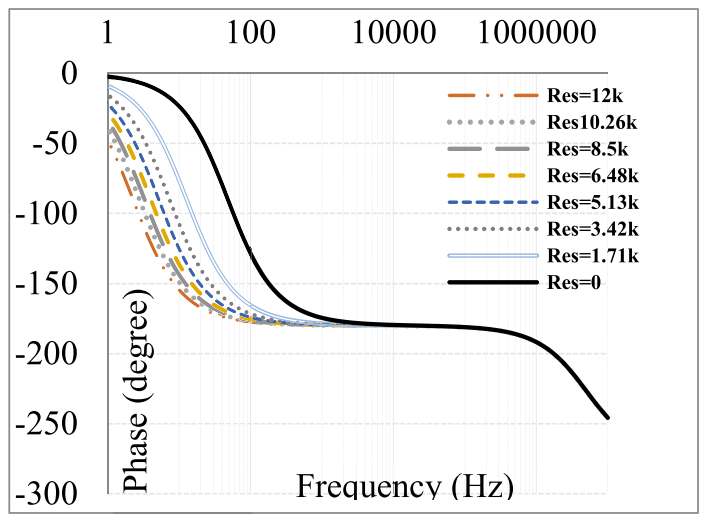

Fig. 14. Phase response for different values of gain for varying $R_{\text {LMA. }}$

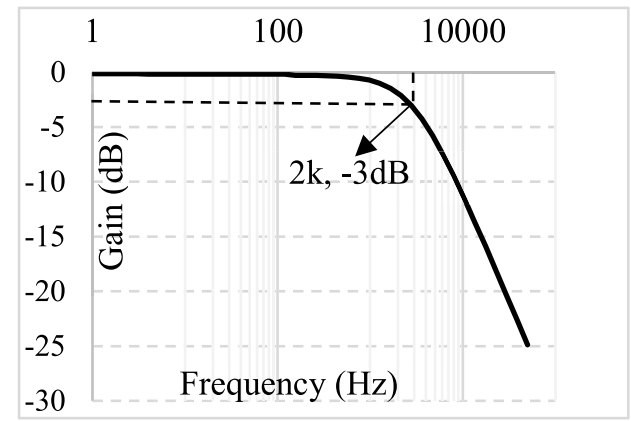

Fig. 15. Simulated magnitude response of the APF in subthreshold.

can take significantly lower values of $\pm 200 \mathrm{mV}$. The circuit was simulated with $I_{B}$ of $100 \mathrm{nA}$, the same transistor sizes as in Section V-A, and with resistors, $R_{\mathrm{OTA}}, R_{L}, R_{M}$, and $R_{\text {LMA }}$ each scaled up by a factor of 100 . Total quiescent power dissipation in this case is $0.64 \mu \mathrm{W}$. Figs. 15 and 16 show the frequency response of the APF operating in these conditions. It has $0.14-\mathrm{dB}$ passband ripple. The $f_{0}$ frequency is at $2.76 \mathrm{~Hz}$. At $2.76-\mathrm{Hz}$ equivalent input noise is $80 \mu \mathrm{V} / \sqrt{ } \mathrm{Hz}$. The equivalent input noise response is shown in Fig. 17. Fig. 18 shows the transient response of the filter for $50-\mathrm{mV}$ amplitude and 2.76- $\mathrm{Hz}$ sinusoidal input signal.

\section{EXPERIMENTAL RESULTS}

A test chip prototype was fabricated (through and thanks to Metal Oxide Semiconductor Implementation Service) in a $0.13-\mu \mathrm{m}$ CMOS $\mathrm{n}$-well process using the same parameters described in Section $\mathrm{V}$ for operation in strong inversion. A

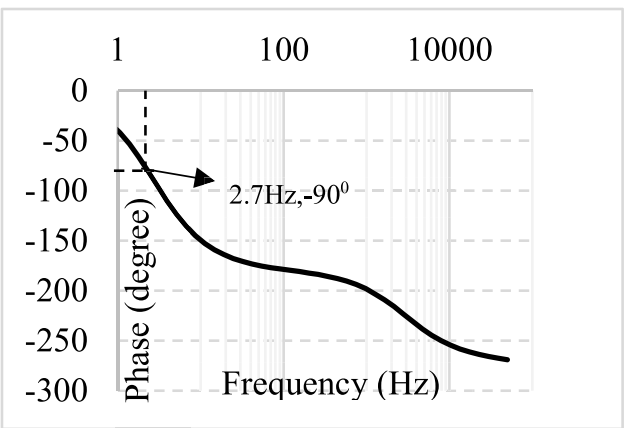

Fig. 16. Phase response of APF at subthreshold.

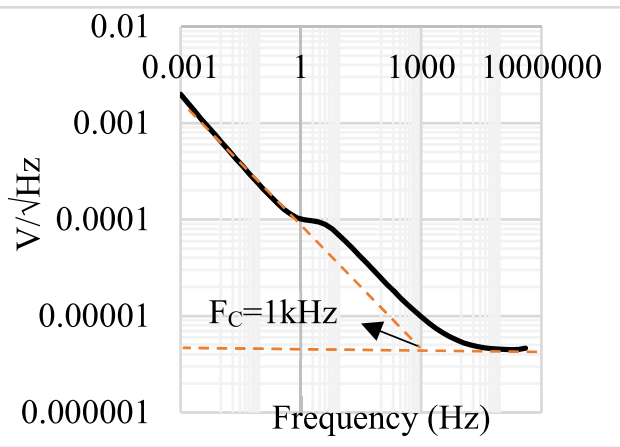

Fig. 17. Equivalent input noise of APF at subthreshold.

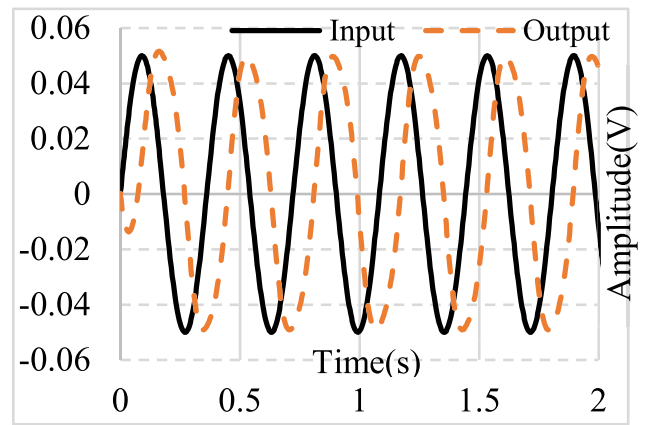

Fig. 18. Transient response of APF at 2.7- $\mathrm{Hz} 50-\mathrm{mV}$ amplitude sinusoidal signal at subthreshold.

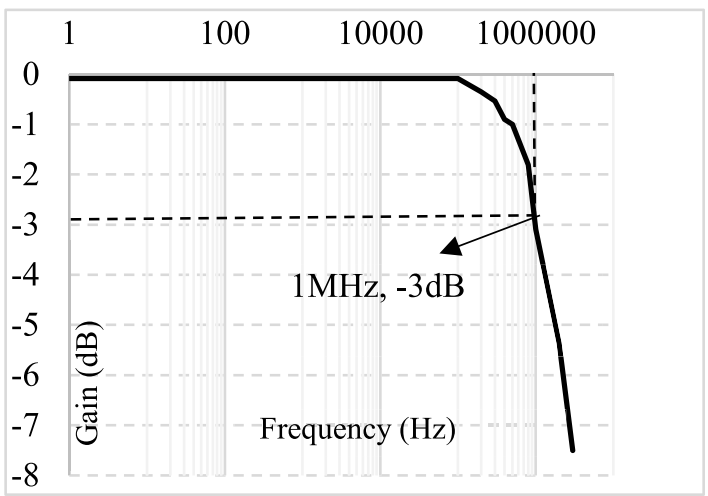

Fig. 19. Experimental magnitude response of APF.

bias current $I_{B}=20 \mu \mathrm{A}$ and $\pm 600 \mathrm{mV}$ were used to test the chip. The load capacitance $C_{L}=25 \mathrm{pF}$ corresponds to the capacitance of the scope probes and the test board. Fig. 19 shows the measured magnitude response of the APF. 
This is the author's version of an article that has been published in this journal. Changes were made to this version by the publisher prior to publication.

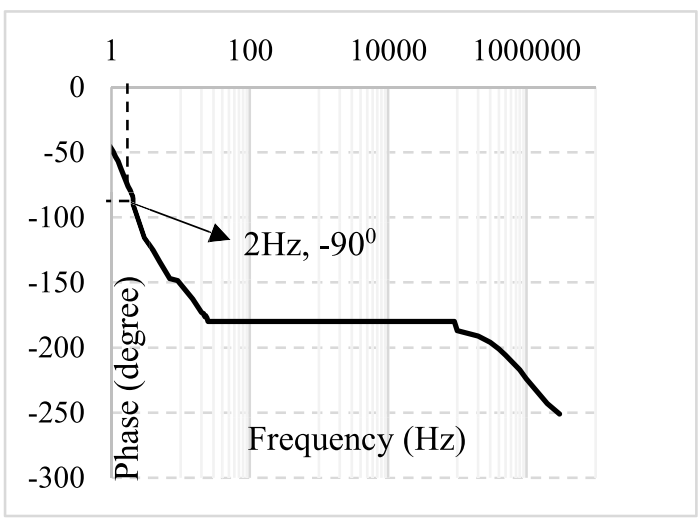

Fig. 20. Experimental phase response of APF.

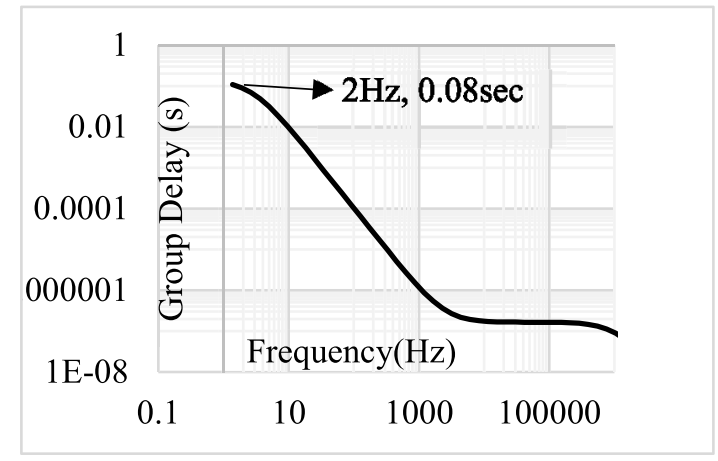

Fig. 21. Simulated GD response of APF.

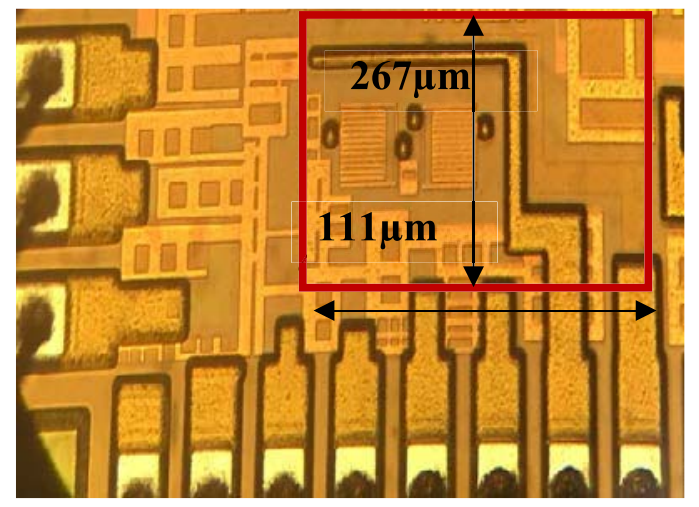

Fig. 22. Micrograph of the fabricated APF.

The experimental magnitude response is constant. At $100 \mathrm{kHz}$, a magnitude deviation of $0.08 \mathrm{~dB}$ is caused by the output pole. Magnitude decreases by $3-\mathrm{dB}$ close to the output pole at $f_{\mathrm{pOut}}=1 \mathrm{MHz}$. The value of the $f_{\mathrm{pOut}}$, BW of the APF obtained from experiment conforms the theoretical value $(1.2 \mathrm{MHz})$ obtained from (8). The measured $f_{0}$ is $2 \mathrm{~Hz}$ as shown in Fig. 20. Fig. 21 shows the simulated GD response. The theoretical value of GD calculated from (7) is $0.08 \mathrm{~s}$ obeys the simulation result. The micrograph of the fabricated circuit is given in Fig. 22. The proposed circuit occupies $0.029 \mathrm{~mm}^{2}$ of silicon area.

Figs. 23-25 show the experimental transient responses of the APF for $0.2,2$, and $25 \mathrm{~Hz}$ for the $400-\mathrm{mVpp}$ amplitude

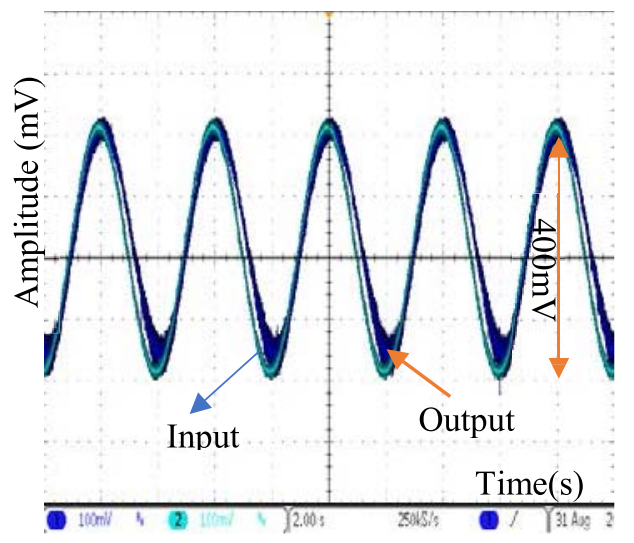

Fig. 23. Experimental transient response at $0.2 \mathrm{~Hz}$.

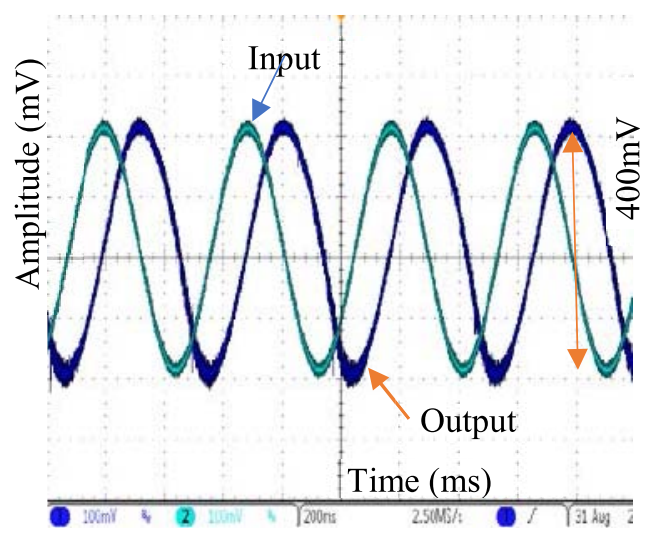

Fig. 24. Experimental transient response at $2 \mathrm{~Hz}$.

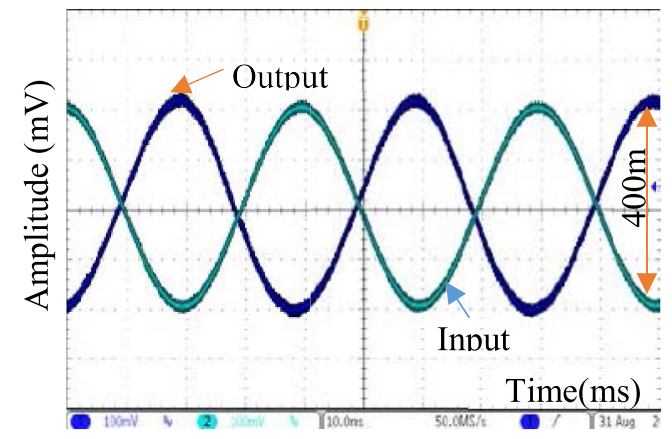

Fig. 25. Experimental transient response at $25 \mathrm{~Hz}$.

sinusoidal signal. It can be observed that at a low-frequency $f=0.2 \mathrm{~Hz}$ input and output signals are in phase. At $2 \mathrm{~Hz}$, there is a $90^{\circ}$ phase shift between input and output signals which have the same amplitude. Finally, the input and output signals are $180^{\circ}$ out of phase at $25 \mathrm{~Hz}$. These results validate the proposed circuit. The quiescent power consumed by circuit of Fig. 1 for a bias current $I_{B}=20 \mu \mathrm{A}$ is $192 \mu \mathrm{W}$. The Miller multiplier consumed $192-\mu \mathrm{W}$ quiescent power. Hence, total $384-\mu \mathrm{W}$ quiescent power is consumed to obtain a $2-\mathrm{Hz}$ pole frequency. Table II gives comparison results of previously published APFs and the proposed APF. From Table II, it can be ascertained that the proposed APF has the lowest $f_{0}$ frequency. 
This is the author's version of an article that has been published in this journal. Changes were made to this version by the publisher prior to publication.

The final version of record is available at https://doi.org/10.1109/TVLSI.2018.2878017

TABLE II

Comparison of Some Published APF With This PAPER

\begin{tabular}{|c|c|c|c|c|c|c|c|c|c|}
\hline & {$[5]$} & {$[2]$} & {$[6]$} & [7] & [8] & [9] & {$[10]$} & This Work & \\
\hline $\begin{array}{l}\text { Process } \\
\text { Technology }\end{array}$ & $\begin{array}{l}130 \mathrm{~nm} \\
\text { CMOS }\end{array}$ & $\begin{array}{l}130 \mathrm{~nm} \\
\text { CMOS }\end{array}$ & $\begin{array}{l}0.7 \mu \mathrm{m} \\
\mathrm{CMOS}\end{array}$ & $\begin{array}{l}0.5 \mu \mathrm{m} \\
\text { CMOS }\end{array}$ & $\begin{array}{l}0.5 \mu \mathrm{m} \\
\mathrm{CMOS}\end{array}$ & $\begin{array}{l}4007 \text { MOS } \\
\text { transistor } \\
\text { arrays }\end{array}$ & $\begin{array}{l}\text { AMS } \\
0.35 \mu \mathrm{m} \\
\text { CMOS }\end{array}$ & $\begin{array}{l}130 \mathrm{~nm} \\
\text { CMOS } \\
\text { (Exp) }\end{array}$ & $\begin{array}{l}130 \mathrm{~nm} \\
\text { CMOS } \\
(\mathrm{Sim})\end{array}$ \\
\hline $\begin{array}{l}\text { Supply } \\
\text { Voltage(V) }\end{array}$ & 1.5 & 1.5 & - & \pm 2.5 & \pm 2 & \pm 2.5 & 1.5 & \pm 0.6 & \pm 0.2 \\
\hline $\begin{array}{l}\text { Bias } \\
\text { Current } \\
(\mu \mathrm{A})\end{array}$ & - & - & - & - & - & $75-350$ & 0.20 & 20 & 0.10 \\
\hline$f_{0}(\mathrm{~Hz})$ & $10 \mathrm{G}$ & $\approx 6 \mathrm{G}$ & $9.68 \mathrm{k}$ & $159 \mathrm{k}$ & $2 \mathrm{k}-2 \mathrm{M}$ & $\approx 50-70 \mathrm{k}$ & $22 \mathrm{k}$ & 2 & 2.76 \\
\hline $\mathrm{BW}(\mathrm{Hz})$ & & & & & & & & $1 \mathrm{M}$ & $2 \mathrm{k}$ \\
\hline $\begin{array}{l}\text { Power } \\
\text { Dissipation } \\
\text { (mW) }\end{array}$ & 24 & 18.5 & - & - & - & - & 0.0003 & 0.38 & 0.00064 \\
\hline $\mathrm{Si}$ area & - & $\begin{array}{l}0.062 \\
\mathrm{~mm}^{2}\end{array}$ & - & - & - & - & - & $\begin{array}{l}0.029 \\
\mathrm{~mm}^{2}\end{array}$ & - \\
\hline THD (dB) & - & - & - & - & - & - & - & $-48^{*}$ & $-40^{* *}$ \\
\hline Noise & $\begin{array}{l}36 \\
\mathrm{pa} / \sqrt{\mathrm{Hz}} \\
@ 10 \mathrm{GHz}\end{array}$ & - & - & - & - & - & $0.03 \mathrm{mVrms}$ & $84 \mu \mathrm{V} / / \sqrt{ } \mathrm{Hz} @ 2 \mathrm{~Hz}$ & $80 \mu \mathrm{V} / / \sqrt{\mathrm{Hz}} @ 2.76 \mathrm{~Hz}$ \\
\hline $\begin{array}{l}\text { Ripple in } \\
\text { pass-band }\end{array}$ & NA & NA & $0.11 \mathrm{~dB}$ & - & - & - & - & $.08 \mathrm{~dB}$ & $0.14 \mathrm{~dB}$ \\
\hline $\begin{array}{l}\text { Experiment } \\
\text {-al } \\
\text { validation }\end{array}$ & No & Yes & Yes & No & No & Yes & No & Yes & No \\
\hline
\end{tabular}

\section{CONCLUSION}

A first-order APF with extremely low $f_{0}$ frequency $(\mathrm{Hz})$ was introduced and verified experimentally with a test chip prototype in 130-nm CMOS technology. To the authors' knowledge, no other APF with such low $f_{0}$ frequency has been reported in the literature. The proposed circuit is based on a linear OTA and provides very low passband ripple. It achieves extremely large time constants $(\sim$ seconds $)$ with low silicon area requirements due to the utilization of quasi-floating gate transistors and Miller capacitors. By varying the gain of the Miller amplifier, variable $f_{0}$ can be achieved. Experimental results substantiate that the proposed APF provides phase quadrature at $2 \mathrm{~Hz}$ and a constant gain from dc to $100 \mathrm{kHz}$. It was verified with simulations that the proposed circuit can also work in the subthreshold region with essentially reduced supply voltages and power dissipation.

\section{REFERENCES}

[1] X. Lai and Z. Lin, "Design and application of allpass filters with equiripple group delay errors," in Proc. IEEE Int. Symp. Circuits Syst. (ISCAS), May 2013, pp. 2924-2927.

[2] P. Ahmadi, B. Maundy, A. S. Elwakil, L. Belostotski, and A. Madanayake, "A new second-order all-pass filter in 130-nm CMOS," IEEE Trans. Circuits Syst. II, Exp. Briefs, vol. 63, no. 3, pp. 249-253, Mar. 2016.

[3] J. Vavra, J. Bajer, and D. Biolek, "Differential-input buffered and transconductance amplifier-based all-pass filter and its application in quadrature oscillator," in Proc. 35th Int. Conf. Telecommun. Signal Process. (TSP), Jul. 2012, pp. 411-415.

[4] S. K. Garakoui, E. A. M. Klumperink, B. Nauta, and F. E. vanVliet, "Frequency limitations of first-order $g_{m}-R C$ all-pass delay circuits," IEEE Trans. Circuits Syst. II, Exp. Briefs, vol. 60, no. 9, pp. 572-576, Sep. 2013
[5] P. Ahmadi, M. H. Taghavi, L. Belostotski, and A. Madanayake, " $10-\mathrm{GHz}$ current-mode $1^{\text {st }}$ - and $2^{\text {nd }}$-order allpass filters on $130 \mathrm{~nm}$ CMOS," in Proc. IEEE 56th Int. Midwest Symp. Circuits Syst. (MWSCAS), Aug. 2013, pp. 1-4.

[6] D. Biolek and V. Biolkova, "Allpass filter employing one grounded capacitor and one active element," Electron. Lett., vol. 45, no. 16, pp. 807-808, Jul. 2009.

[7] C. Cakir, U. Cam, and O. Cicekoglu, "Novel allpass filter configuration employing single OTRA," IEEE Trans. Circuits Syst. II, Exp. Briefs, vol. 52, no. 3, pp. 122-125, Mar. 2005.

[8] S. M. Al-Shahrani, "A novel CMOS wideband auto-tuning phase shifter circuit," in Proc. 14th IEEE Int. Conf. Electron., Circuits Syst., Dec. 2007, pp. 649-652.

[9] A. Toker and S. Ozoguz, "Tunable allpass filter for low voltage operation," Electron. Lett., vol. 39, no. 2, pp. 175-176, Jan. 2003.

[10] C. Sawigun and P. Pawarangkoon, "A 1.5-V, 300-nW, continuous-time allpass filter With $67 \mathrm{~dB}$ dynamic range," in Proc. 11th Int. Conf. Electr. Eng./Electron., Comput., Telecommun. Inf. Technol. (ECTI-CON), May 2014, pp. 1-4.

[11] A. F. Borghesani and M. Santini, "Magnetic rotating disk viscometer," Int. J. Thermophys., vol. 10, no. 5, pp. 917-927, 1989.

[12] E. Rodriguez-Villegas, L. Logesparan, and A. J. Casson, "A low power linear phase programmable long delay circuit," IEEE Trans. Biomed. Circ. Syst., vol. 8, no. 3, pp. 432-441, Jun. 2014.

[13] S. Solis-Bustos, J. Silva-Martinez, F. Maloberti, and E. Sanchez-Sinencio, "A 60-dB dynamic-range CMOS sixth-order 2.4-Hz low-pass filter for medical applications," IEEE Trans. Circuits Syst. II, Analog Digit. Signal Process., vol. 47, no. 12, pp. 1391-1398, Dec. 2000.

[14] K. Furukawa et al., "Measurement of human blood viscosity by an electromagnetic spinning sphere viscometer," J. Med. Eng. Technol., vol. 40, no. 6, pp. 285-292, 2016.

[15] D. A. Fedosov, W. Pan, B. Caswell, G. Gompper, and G. E. Karniadakis, "Predicting human blood viscosity in silico," Proc. Nat. Acad. Sci. USA, vol. 108, no. 29, pp. 11772-11777, 2011.

[16] R. L. Letcher, S. Chien, T. G. Pickering, J. E. Sealey, and J. H. Laragh, "Direct relationship between blood pressure and blood viscosity in normal and hypertensive subjects: Role of fibrinogen and concentration," Amer. J. Med., vol. 70, no. 6, pp. 1195-1202, Jun. 1981. 
[17] K. Furukawa et al., "Increased blood viscosity in ischemic stroke patients with small artery occlusion measured by an electromagnetic spinning sphere viscometer," J. Stroke Cerebrovascular Diseases, vol. 25, no. 11, pp. 2762-2769, 2016.

[18] X. Meng, W. Li, and G. C. Temes, "A fully-differential input amplifier with band-pass filter for biosensors," in Proc. IEEE Int. Symp. Circuits Syst. (ISCAS), Jun. 2014, pp. 21-24.

[19] M. Kachare, A. J. Lopez-Martin, J. Ramirez-Angulo, and R. G. Carvajal, "A compact tunable CMOS transconductor with high linearity," IEEE Trans. Circuits Syst. II, Exp. Briefs, vol. 52, no. 2, pp. 82-84, Feb. 2005.

[20] S.-X. Song, G.-P. Yan, and H. Cao, "A highly linear wide range continuous tuning CMOS OTA," in Proc. 7th Int. Conf. ASIC, Oct. 2007, pp. $588-591$.

[21] J. Ramírez-Angulo, A. J. López-Martín, R. G. Carvajal, and F. M. Chavero, "Very low-voltage analog signal processing based on quasi-floating gate transistors," IEEE J. Solid-State Circuits, vol. 39, no. 3, pp. 434-442, Mar. 2004

[22] A. Torralba et al., "Tunable linear MOS resistors using quasi-floatinggate techniques," IEEE Trans. Circuits Syst. II, Exp. Briefs, vol. 56, no. 1, pp. 41-45, Jan. 2009.

[23] A. L. Martin, J. M. A. Miguel, L. Acosta, J. Ramírez-Angulo, and R. G. Carvajal, "Design of two-stage class AB CMOS buffers: A systematic approach," ETRI J., vol. 33, no. 3, pp. 393-400, 2011.

[24] G. A. Rincon-Mora, "Active capacitor multiplier in miller-compensated circuits," IEEE J. Solid-State Circuits, vol. 35, no. 1, pp. 26-32, Jan. 2000

[25] Y. Xu, P. K. Venkatachala, S. Leuenberger, and U.-K. Moon, "A $7.5 \mathrm{~mW}$ 35-70 MHz 4th-order semi-passive charge-sharing band-pass filter with programmable bandwidth and $72 \mathrm{~dB}$ stop-band rejection in 65 nm CMOS," in Proc. IEEE Radio Freq. Integr. Circuits Symp. (RFIC), May 2016, pp. 162-165.

[26] M. Kachare, J. Ramirez-Angulo, R. G. Carvajal, and A. J. Lopez-Martin, "New low-voltage fully programmable CMOS triangular/trapezoidal function generator circuit," IEEE Trans. Circuits Syst. I, Reg. Papers, vol. 52, no. 10, pp. 2033-2042, Oct. 2005.

[27] R. G. Carvajal et al., "The flipped voltage follower: A useful cell for low-voltage low-power circuit design," IEEE Trans. Circuits Syst. I, Reg. Papers, vol. 52, no. 7, pp. 1276-1291, Jul. 2005.

[28] H. S. Malvar and M. Luettgen, "Temperature compensation of OTA-based filters and amplifiers," Electron. Lett., vol. 23, no. 17, pp. 890-891, Aug. 1987.

[29] Y. P. Tsividis, "Integrated continuous-time filter design," in Proc. IEEE Custom Integr. Circuits Conf. (CICC), May 1993, pp. 6.4.1-6.4.7.

[30] B. Razavi, Design of Analog CMOS Integrated Circuits (Electrical and Computer Engineering). New York, NY, USA: McGraw-Hill, 2005.

[31] Noise Analysis in Operational Amplifier Circuits, Texas Instruments, Dallas, TX, USA, 2007.

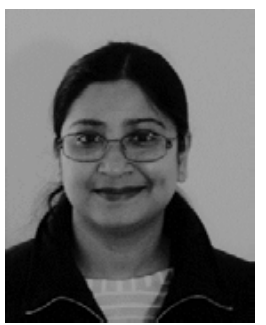

Anindita Paul (S'16) was born in Chinsurah, India. She received the M.Tech. degree in VLSI design from the Institute of Radio Physics and Electronics, University of Calcutta, Kolkata, India. She is currently working toward the Ph.D. degree at the Klipsch School of Electrical Engineering, New Mexico State University, Las Cruces, NM, USA.

Her current research interests include low-voltage low-power analog circuit design.

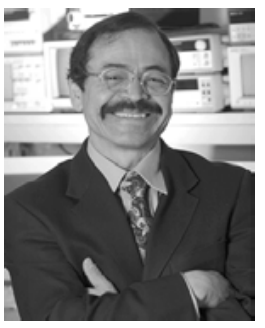

Jaime Ramírez-Angulo (M'82-F'00) received the B.Sc. degree in communications and electronic engineering (Professional degree) and the M.S.E.E. degree from the National Polytechnic Institute, Mexico City, Mexico, in 1974 and 1976, respectively, and the Ph.D. degree from the University of Stuttgart, Stuttgart, Germany, in 1982.

$\mathrm{He}$ was a Professor with the National Institute for Astrophysics Optics and Electronics, Cholula, Mexico, and Texas A\&M University, College Station, TX, USA. He is currently a Distinguished Award Professor with the Klipsch School of Electrical and Computer Engineering, New Mexico State University, Las Cruces, NM, USA, where he is also the Director of the Mixed-Signal VLSI Laboratory. His current research interests include various aspects of design and test of analog and mixed-signal very large scale integrated circuits.

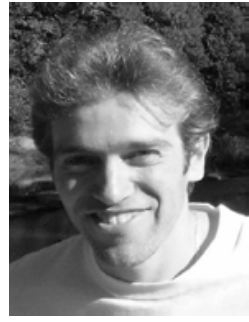

Antonio J. Lopez-Martin (M'04-SM'11) received the M.S. and Ph.D. degrees (honors) from the Public University of Navarra, Pamplona, Spain, in 1995 and 1999, respectively.

He was a Visiting Professor at the New Mexico State University, Las Cruces, NM, USA, and an Invited Researcher with the Swiss Federal Institute of Technology, Zurich, Switzerland. He is currently a Professor at the Public University of Navarra, and an Adjunct Professor with New Mexico State University. $\mathrm{He}$ is a Consultant for local companies. He has authored or coauthored over 400 technical contributions in books, journals, and conferences. He holds six international patents. His current research interests include wireless transceivers and sensor interfaces with emphasis on low-voltage low-power implementations.

Dr. Lopez-Martin is with the Technical Committee of various conferences. He was a recipient of the Talgo Technological Innovation Award in 2012, the ANIT's Engineer of the Year Award in 2008, the Caja Navarra Research Award in 2007, the Young Investigator Award from the Completeness University of Madrid in 2006, the 2005 IEEE Transactions on Education Best Paper Award, and the European Center of Industry and Innovation Award in 2004 for excellence in transfer of research results to industry. He was an Associate Editor of the IEEE TRANS ACTIONS ON CIRCUITS AND SYSTEMS-PART II: EXPRESS BRIEFS from 2006 to 2007 and the IEEE TRANSACTIONS ON Circuits AND Systems-PART I: Regular PAPERS from 2008 to 2009.

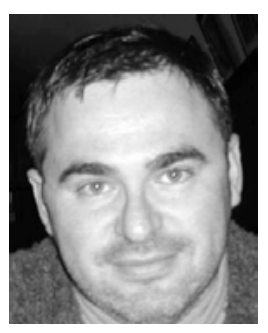

Ramón Gonzalez Carvajal (M'99-SM'04) received the M.Sc. degree in electrical engineering and the Ph.D. degree (Hons.) from the University of Seville, Seville, in 1995 and 1999, respectively. In 1996, he joined the Department of Electronic Engineering, School of Engineering, University of Seville, as an Associate Professor, where he became a Professor in 2002. In 1997, he joined the Electrical Engineering Department, Texas A\&M University, and College Station, TX, USA, as an Invited Researcher. In 1999, he joined the Klipsch School of Electrical Engineering, New Mexico State University, Las Cruces, NM, USA, as an Invited Researcher. From 2001 to 2004, he was an Invited Researcher with the Klipsch School of Electrical Engineering, where he is currently an Adjunct Professor. He has authored or coauthored over 60 papers in international journals. He has authored and 200 papers in international conferences. His current research interests include low-voltage low-power analog circuit design, A/D and D/A conversion, and analog and mixed-signal processing. 